\title{
The effect on plasma lipids of the isoenergetic replacement of table sucrose by dried glucose syrup (maize-syrup solids) in the normal diet of adult men over a period of 1 year
}

\author{
BY SUSAN LOCK*, M. A. FORD, R. BAGLEY \\ AND L. F. GREEN† \\ Beecham Products, $R \& D$ Department, The Royal Forest \\ Factory, Coleford, Glos. GLI6 8JB
}

(Received 3 August $1979-$ Accepted 2I September 1979)

1. Eighteen males (31-62 years) who habitually consumed significant amounts of table sucrose (approximately $25 \%$ of total carbohydrate intake) were supplied with their usual intake of sucrose for consumption in conjunction with their normal diet for 1 year, and a record kept of the amount consumed. The sucrose was then replaced isoenergetically by dried glucose syrup ( 55 D.E.) which contained saccharin to equate the sweetness to that of sucrose.

2. Fasting blood samples were taken every 4 weeks during the 2 years, and the plasma analysed for glucose, cholesterol, triglycerides and phospholipid-P by automated colorimetric methods. Dietary questionnaires were issued every 3 months to confirm that subjects were not substantially altering their diets.

3. In subjects whose weight remained unchanged and in those who lost weight there was a significant fall in cholesterol $(P<0.025)$ and phospholipid-P $(P<0.025)$ in the glucose-syrup period compared with the sucrose period; triglycerides did not change. In subjects who gained weight there was a significant increase in triglycerides $(P<0.05)$, but no change in cholesterol; phospholipid-P fell significantly $(P<0.0005)$.

4. The dietary modification in this experiment was sufficiently long to ensure that subjects had adapted, and the results obtained show stable changes in blood lipids which may be attributed to the isoenergetic replacement of table sucrose by glucose syrup.

In view of the McGovern recommendations (Select Committee on Nutrition and Human Needs, 1977) to increase the dietary intake of complex carbohydrates, and widespread medical advice to reduce the intake of sucrose (Department of Health and Social Security, 1978), it is worth considering the effects, if any, of such dietary modifications on various biochemical measurements in man.

The relationship between different forms of dietary carbohydrate and blood lipids has been recognized for some time (Grande, 1974). However, since there is little information on the long-term effects of changing the form of carbohydrate in the diet, the following investigation was carried out in which table sucrose was replaced isoenergetically by dried glucose syrup (also known as maize-syrup solids) in a group of male volunteers for a period of I year.

Dried glucose syrup is composed of partially-hydrolysed starch from which the water has been removed. A measure of the extent of breakdown of the starch is given by the dextrose equivalent (D.E.); the reducing power expressed as grams of reducing sugars (i.e. anhydrous D-glucose) per Ioo g dry substance.

\section{EX PER IMENT A L}

Eighteen male volunteers (aged $3 \mathrm{I}-62$ years) who habitually consumed significant amounts of table sucrose (approximately $60 \%$ of total sucrose intake, and $25 \%$ of total carbohydrate intake) took part in the trial.

* Present address: Food Research Institute, Colney Lane, Norwich, Norfolk NR4 7 UA.
† Present address: I 2 Broad Reaches, Ludhan, Norfolk NR29 5PD. 
Table I. Daily intake of carbohydrate, fat and protein expressed as proportion of energy in the normal diet of adult men

\begin{tabular}{|c|c|c|c|c|c|c|}
\hline Year & Month & Carbohydrate & Fat & Protein & Alcohol & \\
\hline $\mathbf{r}$ & July & 0.415 & 0.416 & 0.135 & 0.034 & \\
\hline 2 & January & 0.390 & $0.45 \mathrm{I}$ & $0 \cdot \mathrm{I} 3 \mathrm{I}$ & 0.028 & \\
\hline 2 & April & 0.419 & 0.400 & 0.136 & 0.045 & Sucrose \\
\hline & Mean & 0.408 & 0.422 & 0.134 & 0.0361 & \\
\hline 2 & August & 0.415 & 0.402 & 0.142 & $0.04 I^{1}$ & \\
\hline 3 & April & $\begin{array}{l}0.418 \\
0.416\end{array}$ & $\begin{array}{l}0.413 \\
0.408\end{array}$ & $\begin{array}{l}0.137 \\
0.140\end{array}$ & $\left.\begin{array}{l}0.032 \\
0.036\end{array}\right\}$ & Glucose \\
\hline
\end{tabular}

Dietary questionnaires were used to assess their daily sucrose intake, and for I year all table sucrose was supplied ad lib. in individual, $6.5 \mathrm{~g}$ (i.e. one teaspoonful) coded sachets, or in I lb (approximately $500 \mathrm{~g}$ ) jars. The sucrose was provided in two different physical forms (crystalline and powdered) in an attempt to mask the actual experimental design, and subjects were led to believe that they were taking different table sweeteners. A record was kept of the amount consumed; the mean daily consumption was approximately $60 \mathrm{~g}$. Throughout the experiment subjects continued with their otherwise normal diet.

After I 2 months the sucrose was replaced isoenergetically by dried glucose syrup ( 55 D.E.) which contained saccharin to equate the sweetness to that of sucrose. The glucose syrup was provided in two physical forms, parallel to those of sucrose.

Fasting blood samples were taken every 4 weeks, and subjects weighed at the same time. Dietary questionnaires were issued five times throughout the 2 years to confirm that subjects were not substantially altering their diets. They were asked to recall what they had eaten for $2 \mathrm{~d}$, and the mean nutrient intake was calculated from food tables (McCance \& Widdowson, 1967).

The blood samples were heparinized and the plasma analysed for glucose (glucose oxidase-peroxidase method, Boehringer Corporation), cholesterol (Fosbrooke \& Pringle, 1970), triglycerides (Noble \& Campbell, 1970), and phospholipid-P (Zilversmit \& Davis, 1950) by automated colorimetric methods.

\section{RESULTS}

The mean daily intake of carbohydrate, fat, protein and alcohol, expressed as a proportion of the energy consumed, at various time intervals throughout the trial, is shown in Table I. No major changes were observed.

Statistical assessment of the results of the plasma analyses confirmed the subjective view gained during the trial that for the first 5 months the subjects found it difficult to completely fulfil the fasting requirements. Thus it was decided to accept as a basis of comparison information obtained over the last 7 months only of each treatment.

Because of the influence of weight gain on blood lipids (Anderson et al. 1957), the subjects were subdivided into three groups according to their difference in weight between the last 7 months of the sucrose period and the last 7 months of the glucose-syrup period (paired $t$ test $P<0.05$ ). Group I ( $n$ 8), no significant change in weight; group 2 ( $n$ 5), significant increase in weight; group $3(n)$ ), significant decrease in weight.

The mean weight of each group (kg; \pm SD) for the sucrose and glucose syrup periods respectively were: group $\mathrm{I}, 72.8( \pm 6.4)$ and $72.9( \pm 6.3)$; group $2,73.1( \pm 6.7)$ and 76.9 $( \pm 7 \cdot 7)$; group $3,78 \cdot 4( \pm 16 \cdot 9)$ and $71 \cdot 9( \pm 13 \cdot 2)$.

Since blood lipids show seasonal variation (Thomas et al. 196r; Fyfe et al. 1968) the results were treated as follows. For each month the mean result of each variable was computed for all individuals in a group. Then, the mean value in the sucrose period was 
compared by a paired $t$ test with the mean value in the corresponding glucose-syrup period.

The mean fasting plasma values during the sucrose and glucose-syrup periods for all three groups are shown in Table 2. In subjects whose weight remained unchanged (group I) and in those who lost weight (group 3) there was a significant fall in plasma cholesterol and phospholipid-P in the glucose-syrup period compared with the sucrose periods; triglycerides did not change. In subjects who gained weight (group 2) there was no change in plasma cholesterol, but phospholipid-P fell significantly; triglycerides rose significantly.

In the absence of any evidence to the contrary, it is assumed that fasting blood glucose levels are not dependent on the time of year, and therefore the mean values for each individual over the two 7-month treatment periods were computed and the two sets of values compared by means of a paired $t$ test. The only significant change was a small rise in fasting blood glucose during the glucose-syrup period in subjects who gained weight (group 2).

\section{DISCUSSION}

There is substantial evidence that the ingestion of sucrose results in higher plasma lipid levels than with glucose or starch (Grande, 1974). However, for reasons of cost and convenience, many human experiments carried out to investigate the effects of different carbohydrates on physiological measurements have been relatively short-term, lasting in some instances only several weeks. As commented by Dunnigan et al. (1970), there is a need for long-term comparative studies of starch and sucrose feeding to establish if differences in serum lipids and glucose tolerance will arise which are not evident in the short-term experiments.

An illustration of the importance of the duration of the dietary period is given by work carried out by Groen et al. (1966). When starch (in the form of bread) replaced sucrose in the diet of adult subjects, there was no change in serum cholesterol after 2 weeks, but after 4-5 weeks there was a significant fall in serum cholesterol in the starch group.

The present experiment, in which the dietary modification was of I year's duration, was sufficiently long to ensure that subjects had adapted. Thus the results obtained show stable changes in blood lipids which may be attributed to the isoenergetic replacement of table sucrose by glucose syrup. The mean drop in cholesterol was $8 \%$ which is similar to the drop in cholesterol obtained by Jenkins et al. (I979) when they gave subjects the hypocholesterolaemic agent, cholestyramine.

The mean changes in cholesterol for all three groups is shown in Fig. I. There appear to be seasonal variations, and the changes under the glucose-syrup period are greater. There were very tight analytical controls practised throughout the 2 years, using samples of standard sera. Thus the changes in cholesterol seen are in fact real, and not the result of fluctuations in analytical procedures.

Fasting glucose values showed some fluctuation, as illustrated in Fig. 2. There was no pattern to the changes, but the short-term variability of these biochemical measurements, whether seasonal or not, does emphasize the importance of measuring blood variables several times in order to obtain a representative value. It has been reported by Bender (1976) that fasting serum lipids do fluctuate even from day to day.

In conclusion, it was found in this experiment that the isoenergetic replacement of table sucrose by dried glucose syrup in male adults for a period of I year resulted in a statisticallysignificant fall in fasting plasma cholesterol and phospholipid-P in subjects who exhibited no weight change and in those who lost weight. Their fasting triglycerides remained unchanged. In subjects who gained weight, there was a significant fall in fasting phospholipid-P but no change in cholesterol. Fasting triglycerides rose significantly. 


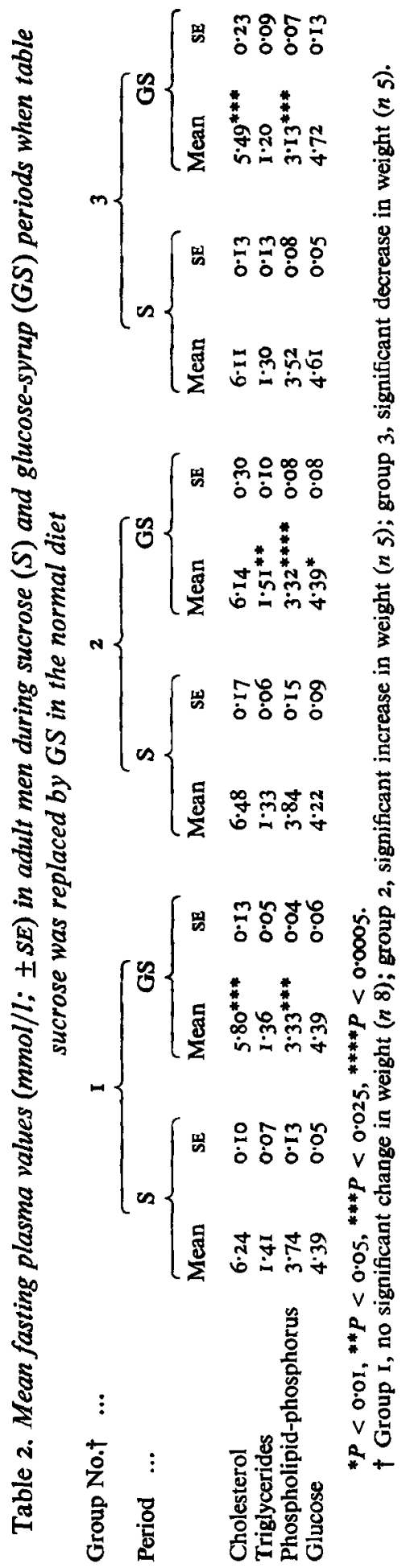




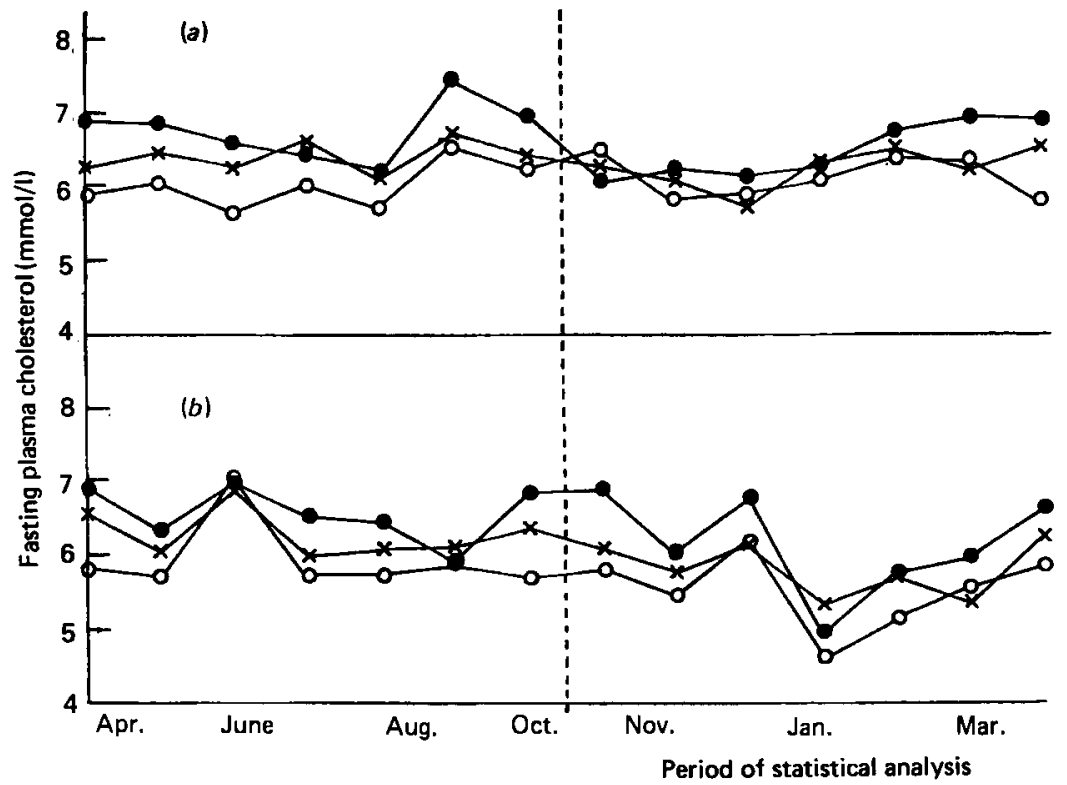

Fig. 1. Changes in cholesterol over 2 years in adult men given isoenergetic amounts of $(b)$ dried glucose syrup instead of $(a)$ table sucrose in their normal diet. $\times-\times$, group I (no significant change in weight); - - group 2 (significant increase in weight); $\bigcirc-\bigcirc$, group 3 (significant decrease in weight). $99 \%$ confidence limit ( $\pm 0.2 \mathrm{I})$.

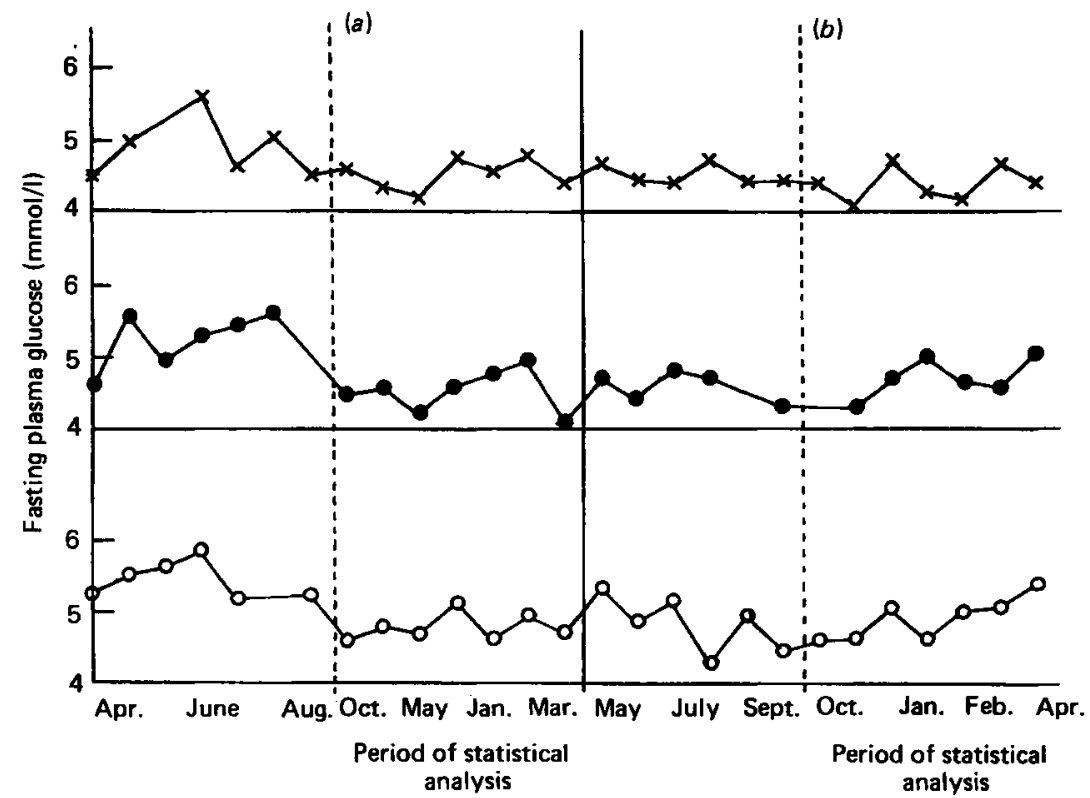

Fig. 2. Fluctuations in plasma glucose in three subjects over 2 years. $\times-\times$, group I (no significant change in weight); - 0 , group 2 (significant increase in weight); $\bigcirc-\bigcirc$, group 3 (significant decrease in weight $) .99 \%$ confidence limit $( \pm 0.086)$. 
It is fairly well accepted that there is a relationship between triglycerides, cholesterol and coronary heart disease. If the hypothesis is correct, it might therefore be advantageous to partially replace sucrose with glucose syrup in the diet.

\section{REFERENCES}

Anderson, J. T., Lawler, A. \& Keys, A. (I957). J. clin. Invest. 36, 81.

Bender, D. A. (1976). Proc. Nutr. Soc. 35, I46A.

Department of Health and Social Security (1978). Eating for Health. London: H.M. Stationary Office.

Dunnigan, M. G., Fyfe, T., McKiddie, M. T. \& Crosbie, S. M. (1970). Clin. Sci. 38, 1.

Fosbrooke, A. \& Pringle, G. (1970). Clinica chim. Acta 30, 47.

Fyfe, T., Dunnigan, M. G., Hamilton, E. \& Rae, R. J. (1968). J. Atheroscler. Res, 8, 59I.

Grande, F. (1974). In Sugars in Nutrition, p. 401. [H. L. Sipple and K. W. McNutt, editors]. New York: Academic Press.

Groen, J. J., Balogh, M., Yaron, E. \& Cohen, A. M. (I966). Am. J. clin. Nutr. I9, 46.

Jenkins, D. J. A., Reynolds, D., Slavin, B., Leeds, A. R., Waller, A. L. \& Jepson, L. M. (I979). Proc. Nutr. Soc. (In the Press.)

McCance, R. A. \& Widdowson, E. M. (1967). Spec. rep. Ser. med. Res. Counc. no. 297.

Noble, R. \& Campbell, F. (1970). Clin. Chem. 16, I66.

Select Committee on Nutrition and Human Needs (1977). Dietary Goals for the United States, 2 nd ed. Washington, DC: United States Senate, US Govt Printing Office.

Thomas, C. B., Holljes, H. W. D. \& Eisenberg, F. F. (196I). Ann. intern. Med. 54, 413.

Zilversmit, D. \& Davis, A. (1950). J. Lab. clin. Med. 35, 155. 